\title{
The Relationship between Burnout and Organizational Commitment among Nurses at Tanta University Hospitals
}

\author{
Safaa Mohamed El-Demerdash ${ }^{1}$, Afaf Abdelaziz Basal ${ }^{2}$, \\ Ghada Abdelsalam Aldeeb ${ }^{3}$ \\ Nursing service Administration ${ }^{1}$, Medical Surgical Nursing ${ }^{2}$, Faculty of Nursing, Tanta University. Nursing \\ Service Administration ${ }^{2}$, Faculty of Nursing, Monufia University. Egypt.
}

\begin{abstract}
Burnout is a familiar term for today's health care professionals with emotional, psychological, physical, and social consequences for those who experience it. It leads to job dissatisfaction, low organizational commitment, absenteeism, as well as inter personal conflict in teams and patient care. The commitment of nurses is a worldwide concern which is necessary to describe their commitment and what keep them committed in nursing and hospitals. it is an undeniable fact that organizations need workers with high commitment and low burnout levels more than ever before. Aim : The aim of the study was to explore the relationship between nurses burnout on organizational commitment among nurses in selected department (emergency and intensive care units of medical and surgical, , cardiovascular intensive care units,) and general medical surgical departments) at Tanta University Hospitals. Material and method: Correlation design was used. the study was conducted at Tanta University Hospitals, The sample consisted of (123) staff nurses from emergency and intensive care units $N=75)$ and medical-surgical departments $(N=48)$ at Tanta University Hospitals. Two tools were used for data collection, first; Maslach Burnout Inventory which included 22 questions cover areas of: 1-emotional exhaustion (8question), personal accomplishment ( 8 questions) and depersonalization (6questions), second organizational commitment questionnaire It included 39questions divided into eight categories namely: feeling experienced at work(2 questions) 1-2,perceived strategy(1questions) 3, perceived identification with hospital (9questions) 4-12,Equity(1questions)13 investment(9questions)14 -22,, trust(3questions) 23-25, resistance(4 questions) 26-30, grievance(1questions)31, compliance(2questions) 32-33and participation(7 questions)34-39. Results: two third of staff nurses (66.6\%) in general medical surgical departments experienced high level of total burnout compared to $60 \%$ of staff nurses in emergency or intensive care units have the same level of total burnout. Three fourth of staff nurses $(75.6 \%)$ have moderate level of total organizational commitment. in emergency or intensive units and general medical surgical units. There were negative correlations between organizational commitment and Emotional Exhaustion $(r=-0.36)$. Also, there is statistical significant negative correlations between organizational commitment and Accomplishment $(r=-0.42)$. However, non-significant correlation was observed between organizational commitment and Depersonalization. Conclusion: High percent of staff nurses. in emergency or intensive units and general medical surgical units experienced high level of burnout and moderate level of organizational commitment. It recommended that work redesign plans as well as early assessment and intervention may be helpful in the reduction of job burnout in staff nurse working in hospitals.
\end{abstract}

Key wards: Burnout, Nurses, Organizational commitment,

\section{Introduction}

The nursing profession is a highly stressful occupation Individuals working in the human service professions are particularly at risk for developing burnout as a result of an emotionally draining occupation (White $2006^{(1)}$, Carolina 2010) ${ }^{(2)}$. Nurses are particularly susceptible to the development of burnout, mainly because of the nature and the emotional demands of their profession especially intensive care nurses have heavy workloads and extensive responsibilities(Fazelzadeh etal 2008) ${ }^{(3)}$. Burnout has its origins in physical, emotional or psychological demands as well as institutional demands(Hall 2006) ${ }^{(4)}$ Nurse burnout is a condition where a nurse experiences chronic fatigue, exhaustion, tiredness, anger, irritability, frequent headaches, gastrointestinal disturbances, abnormal weight gain or loss, depression, insomnia and breathing difficulties on account of work stress affecting professional performance(Aleandri et.al, 2006) ${ }^{(5)}$.

Burnout is a physical, mental, and emotional response to constant high levels of stress and ineffective or inadequate coping methods(White 2006$)^{(1)}$. It is typically conceptualized as a syndrome characterized by emotional exhaustion, depersonalization, and reduced personal accomplishment(Jennings 2008) ${ }^{(6)}$. Emotional exhaustion refers to feelings of being emotionally overextended and drained by one's contact with other people. Depersonalization refers to an unfeeling and callous response toward these people, who are usually the 
recipients of one's service or care. Reduced personal accomplishment refers to a decline in one's feelings of competence and successful achievement in one's work with people(Gemlik et al2010) ${ }^{(7)}$.

The causes of burnout suggested by the researchers may include the low pay package, excessive work, lack of support from supervisor and colleagues, lack of equipment to work with and public criticism (Malik etal 2010) ${ }^{(8)}$.Matin et al $(2012)^{(9)}$ expound burnout consequences in two job performance and health aspects. In terms of job performance, burnout accompanies with job withdrawal, absenteeism, intention to leave and turnover. Those people who keep their work despite of their burnout are facing with productivity and effectiveness decrease. Accordingly, burnout accompanies with job satisfaction decrease as well as job or organizational commitment mitigation.

Furthermore, burnout is a form of chronic job stress, which significantly related to negative outcomes for organizations, including turnover intention, lack of job satisfaction and organizational commitment (Salahian etal 2012) ${ }^{(10)}$.Several researches are done to study the impacts of burnout on such variables as the intention to leave, job satisfaction and organizational commitment in different jobs (Matin 2012) ${ }^{(9)}$. Burnout causes that people lose interest in their work, reduce their efficiency, undermine inputs and performance of themselves or others, behave in a manner that encourages others to reduce the input, or behave in a manner that change their input and leave their jobs(Aghaei et al 2012) ${ }^{(11) .}$

Organizational Commitment was defined as a multidimensional concept embracing an employee's desire to remain in an organization, willingness to exert effort on its behalf, and belief in and acceptance of the values and goals of the organization.( Singh etal,2008) ${ }^{(12)}$.The most commonly used definition of organization commitment belongs to Allen and Meyer 1990) (13) "a psychological state that binds the individual to the organization." Many factors influence commitment:: feeling experienced at work, identification, trust, investment, participation, effort, and equity(El-Shaer2002 $)^{(14)}$. Researchers divide organizational commitment to three distinct psychological stages (processes): Compliance, identification, and internalization. Compliance means that the person recognizes influence of others because he/she is expecting to obtain something tangible from others, whereas influence suggests that the person accepts influence in order to "maintain a satisfying, selfdefining relationship" (Kalliny, etal 2011) ${ }^{(15)}$.

Finally, the individual internalizes, that is, he/she finds the values of the organization to be congruent with his/her personal values. This categorization is similar to Meyer, and Allen 1991) ${ }^{(16)}$ categorization who define organizational commitment as a multidimensional construct. Accordingly, organizational commitment has three types, namely affective commitment, continuance commitment, and normative commitment. Affective commitment implies employees' emotional attachment to the organization. Continuance commitment refers to employees' feelings of obligation to remain with the organization. Normative commitment is based on the costs that employees would have to incur if they decided to leave the organization. Each dimension is thought to contribute to an employee's relationship with the organization, has implications for his/her continuing membership, and may be affected by different antecedents or may have different consequences (Meyer and Allen, 1991) ${ }^{(16)}$.

The consequences of burnout have serious implications for nurses, nurse educators, students, educational institutions, and ultimately the profession. The worst impact of burnout at the organizational level is destroying and diminishing organizational commitment among personnel and experts of the job. Therefore, organizational commitment has been a subject of much interest in the area of organizational development. Therefore, studying the relation between nurses burnout and organizational commitment is important in improving the quality of health care through investigating the factors that affect both. Hence, the present study has attempted to study the relationship between nurses burnout on organizational commitment among nurses in selected department at Tanta University Main Hospitals .

\section{Aim of the study}

The aim of this study was to study the relationship between burnout and organizational commitment among nurses in selected departments at Tanta University Hospitals. Egypt.

\section{Research questions:}

1- What is the level of burnout among nurses in emergency units and general medical surgical departments

1. What is the level of organizational commitment among nurses in emergency units and general medical surgical departments

3- What is the relationship between burnout and organizational commitment among nurses in emergency units and general medical surgical departments.

\section{Subject and methods}

Research design: correlation research design was used 
Setting: Tanta University Hospital in (emergency and intensive care units of medical and surgical, cardiovascular intensive care units,) and general medical surgical departments.

Sample: A sample of all available 123 staff nurses at Tanta University hospitals at time of study in emergency or intensive care units and general medical surgical department accepted enrolled in this study. Number of nurses in emergency and intensive care units : medical, neurological cardiovascular, chest and, emergency medical intensive care units $(\mathrm{N}=75)$, while number of nurse in general- medical surgical department $\mathrm{N}=48$

\section{Tools of data collection}

To achieve the aims of the study the following tools were used and consists of three parts :

- Part one: was intended to get information about Subject characteristics such as nurses age, marital status, number of children, qualification and years of experience .

- Part two: this part of the nurses burnout questionnaire by( Maslach ) in Abd Elghany F. (2003). ${ }^{(17)}$ It included 22 items cover areas of: emotional exhaustion (8question), personal accomplishment ( 8 questions) and depersonalization (6questions).

- Scoring system

The subject's responses in this part were scored in sex point Likert scale (1-6) ranging from never to every day, every day(6), few times a week(5), once a week(4), few times a month( 3), once a month (2), few times a year(1)and never (Zero). Score of burnout subscale as following:

\begin{tabular}{|c|c|c|c|}
\hline Score & Emotional exhaustion(EE) & Depersonalization (DP) & Personal Accomplishment (PA) \\
\hline Low & $0-16$ & $0-6$ & +39 \\
\hline Moderate & $17-26$ & $7-12$ & $32-38$ \\
\hline High & +27 & $32-38$ & $0-31$ \\
\hline
\end{tabular}

- Total burnout score
1 -High $\geq 68$
2-Moderate: 61- 67
3-Low: $\leq 60$

Higher scores of EE, DP and a lower score of PA indicate a higher level of burnout.

- Part three: this part of the organizational commitment questionnaire by El-Shaer (2002) ${ }^{(14)}$ It included 39 items divided into eight categories namely: feeling experienced at work(2 questions) 1-2,perceived strategy(1questions) 3, perceived identification with hospital (9questions) 4-12 ,Equity(1questions)13 investment(9questions)14 -22, trust(3questions) 23-25, resistance(4 questions) 26-30, grievance(1questions)31, compliance(2questions) 32-33and participation(7 questions)34-39.

\section{Scoring system}

The subject's responses in part three were scored in five point Likert scale (5-1) ranging from strongly agree to strongly disagree, strongly agree (5), agree(4), neutral(3), disagree(2) and strongly disagree(1). The maximum scores of nurses organizational commitment were 195 , these scores were classified into three categories according to the following strength :

1-High 75\% and more 2-Moderate 50-74\% 3-Low $49 \%$ and less

\section{Methods}

\section{- Ethical\& administration considerations:-}

1-An official permission to carry out the study was obtained from responsible authorities of Tanta University Hospitals.

2-Informed consent was obtained from each studied subjects included in the study. The anonymity and confidentiality of responses, voluntary participation and right to refuse to participate in the study were emphasized.

3-The purpose of the study was explained and made clear to the general supervisor of study setting to get their co-operation and acceptance.

4-Pilot study was conducted on 10 percent of staff nurses were enrolled in this study to identify the obstacles and problems that may be encountered in data collection.

\section{-Field work:-}

5-The questionnaire submitted to ten experts from nursing field of nursing administration, critical care and adult care The content validity of the study tools was measured tool (1) $89.4 \% \&$ tool(2) $94.53 \%$.

6-Reliability of the tools was tested using Cronbach coefficient Alpha test, tool (1) .758 and tool (2) .774 
7-The questionnaires were distributed to staff nurses $(n=123)$. Before the questionnaire was administered, the subjects were thoroughly briefed about the study and the data collection process. They were also assured of their anonymity purpose of the confidentiality of their responses.

8-The data collection were completed during the period of two months ( January-February 2012 ) .

9-Questionnaire was collected through semi structured interview, the researchers explain the sheet to the subjects and then, ask them to complete it. Responding times to all questions in the tool consumes(20) minute.

\section{Limitation of the study:}

Some nurses refused to participate in the study.

\section{Statistical analysis:}

Data were analyzed using Statistical Package for Social Sciences (SPSS) Software Package Version 18.0 (SPSS, Chicago, IL, USA). Data was collected, coded and organized into tables, and then analyzed using number and percent qualitative variable are statistically compared using qui square.

\section{Results:}

Table (1): showed characteristics of staff nurses in emergency or intensive units and general medical surgical department including age, marital status, number of children, qualification and years of experience. It was observed that there were no statistical significance differences between both groups (emergency and general medical surgical department nurses) in relation to age, education, marital status and experience. More than half of staff nurses(58.7\% and 68.8\%)respectively, enrolled in the study in emergency and general department their age more than 25 years .Mean of age were $30.34 \pm 7.15$ years. In relation to level of education $80.0 \%$ and $87.5 \%$ respectively were diploma degree. Majority $(77.3 \%$ and $87.5 \%)$ respectively of nurses in both departments were married .Also majority $(74.7 \% \& 75.0 \%)$ respectively of staff nurses had experience more than 5 year respectively and mean of experience per year was $7 \pm 6.13$ years .

Table(2): showed Levels of staff nurses burnout in emergency or intensive care units and general medical surgical departments. It was observed that two third of staff nurses $(66.6 \%)$ in general medical surgical departments experienced high level of total burnout compared to $60 \%$ of staff nurses in emergency or intensive care units have the same level of total burnout. .It was noticed that $18.6 \%$ of staff nurses in emergency or intensive units experienced moderate level of total burnout while low percent (10.4\%) of staff nurses in general medical surgical departments have the same level of total burnout. But nearly equal percent $(21.4 \%, 22.9 \%)$ of staff nurses in emergency or intensive care units and general medical surgical departments experienced low level of total burnout. Moreover there were no significant differences between both units.

Specifically, in relation to emotional exhaustion table 2, it was found that more than half of staff nurses in general medical surgical and emergency or intensive care units experienced high level of emotional exhaustion, but percentage of staff nurses in general medical surgical departments experienced high level of emotional exhaustion higher than staff nurses in emergency or intensive care units $66.7 \%$ and $53.3 \%$ respectively. As evidence in table 2 all staff nurses in emergency or intensive care units experienced high level of depersonalization while $97.1 \%$ staff nurses in general medical surgical departments experienced the same level of depersonalization. It was noticed that there is no one of study nurses in both units have moderate level of depersonalization. As regard accomplishment, all staff nurses in general medical surgical departments in our study experienced low level of accomplishment while $97.1 \%$ staff nurses in emergency or intensive care units experienced the same level of accomplishment. It was noticed that there is no one of study nurses in both units have high level accomplishment.

Table(3): showed Levels of staff nurses organizational commitment in emergency or intensive care units and general medical surgical departments . As evidence in table 3 , there were no statistical significant differences between staff nurses levels of organizational commitment in emergency or intensive care units and general medical surgical departments. Low percent of staff nurses (17.9\%) have high level of total organizational commitment in emergency or intensive care units and general medical surgical departments . Lowest percent of staff nurses $(6.5 \%)$ have low level of total organizational commitment in emergency or intensive care units and general medical surgical departments Specifically, more than three fourth of staff nurses $(78.7 \%)$ in emergency or intensive care units have moderate level of organizational commitment. compared to $70.8 \%$ of staff nurses in general medical surgical departments have the same level.. $25.0 \%$ of staff nurses in general medical surgical departments have high level of organizational commitment while $13.3 \%$ of staff nurses in emergency or intensive care units have the same level.. The lowest percent $(8.0 \% \& 4.2 \%)$ of staff nurses burnout in emergency or intensive care units and general medical surgical departments have low level of organizational commitment

(Table (4): Showed Correlation between level of staff nurses organizational commitment and level of staff nurses burnout component. There were negative correlations between organizational commitment and 
emotional exhaustion $(\mathrm{r}=-0.36)$. Also, there was statistical significant negative correlations between organizational commitment and accomplishment $(\mathrm{r}=-0.42)$. However, non-significant correlation was observed between organizational commitment and depersonalization. There was no significance difference correlation between commitment and total burnout. Also there was negative correlation between burnout and years of experience and there were non significant differences between organizational commitment and burnout and years of experience.

Table (1) characteristics of staff nurses in emergency or intensive and general medical surgical departments

\begin{tabular}{|c|c|c|c|c|c|c|}
\hline \multirow{3}{*}{ Characteristics } & \multicolumn{4}{|c|}{ Department } & \multirow{3}{*}{ Chi-square } & \multirow{3}{*}{ p-value } \\
\hline & \multicolumn{2}{|c|}{ Emergency $(n=75)$} & \multicolumn{2}{|c|}{ General $(\mathrm{n}=48)$} & & \\
\hline & No & $\%$ & No & $\%$ & & \\
\hline $\begin{array}{l}\text { Age } \\
<25 \text { years old }\end{array}$ & 31 & $41.3 \%$ & 15 & $31.3 \%$ & \multirow[t]{2}{*}{1.3} & \multirow[t]{2}{*}{0.3} \\
\hline$>25$ years old & 44 & $58.7 \%$ & 33 & $68.8 \%$ & & \\
\hline Mean \pm SD & \multicolumn{6}{|c|}{$30.34 \pm 7.15$} \\
\hline $\begin{array}{l}\text { Education } \\
\text { Diploma }\end{array}$ & 60 & $80.0 \%$ & 42 & $87.5 \%$ & \multirow[t]{2}{*}{1.2} & \multirow[t]{2}{*}{0.3} \\
\hline Bachelor & 15 & $20.0 \%$ & 6 & $12.5 \%$ & & \\
\hline $\begin{array}{l}\text { Marital Status } \\
\text { Single }\end{array}$ & 16 & $21.3 \%$ & 5 & $10.4 \%$ & \multirow{2}{*}{2.5} & \multirow{2}{*}{0.3} \\
\hline Married & 58 & $77.3 \%$ & 42 & $87.5 \%$ & & \\
\hline Divorced & 1 & $1.3 \%$ & 1 & $2.1 \%$ & & \\
\hline $\begin{array}{l}\text { Duration of Experience } \\
<5 \text { years }\end{array}$ & 19 & $25.3 \%$ & 12 & $25.0 \%$ & \multirow[t]{2}{*}{0.0} & \multirow[t]{2}{*}{1.0} \\
\hline$>5$ years & 56 & $74.7 \%$ & 36 & $75.0 \%$ & & \\
\hline Mean \pm SD & \multicolumn{6}{|c|}{$7.08 \pm 6.13$} \\
\hline
\end{tabular}

Table( 2) Levels of staff nurses burnout in emergency or intensive and general medical surgical departments

\begin{tabular}{|c|c|c|c|c|c|c|}
\hline \multirow{3}{*}{ Burnout subscale } & \multicolumn{4}{|c|}{ Departments } & \multirow{3}{*}{ Chi-square } & \multirow{3}{*}{ p-value } \\
\hline & \multicolumn{2}{|c|}{ Emergency $(n=75)$} & \multicolumn{2}{|c|}{ General $(n=48)$} & & \\
\hline & No & $\%$ & No & $\%$ & & \\
\hline $\begin{array}{l}\text { Emotional Exhaustion } \\
\text { High }\end{array}$ & 40 & $53.3 \%$ & 32 & $66.7 \%$ & \multirow{3}{*}{2.4} & \multirow{3}{*}{0.3} \\
\hline Moderate & 18 & $24.0 \%$ & 7 & $14.6 \%$ & & \\
\hline Low & 17 & $22.7 \%$ & 9 & $18.8 \%$ & & \\
\hline $\begin{array}{l}\text { Depersonalization } \\
\text { High }\end{array}$ & 75 & $100.0 \%$ & 47 & $97.9 \%$ & \multirow[t]{2}{*}{1.6} & \multirow[t]{2}{*}{0.2} \\
\hline Low & 0 & $.0 \%$ & 1 & $2.1 \%$ & & \\
\hline $\begin{array}{l}\text { Accomplishment } \\
\text { Moderate }\end{array}$ & 2 & $2.7 \%$ & 0 & $0 \%$ & \multirow{2}{*}{1.3} & \multirow{2}{*}{0.3} \\
\hline Low & 73 & $97.3 \%$ & 48 & $100.0 \%$ & & \\
\hline $\begin{array}{l}\text { Total Burnout } \\
\text { High }\end{array}$ & 45 & $60 \%$ & 32 & $66.6 \%$ & \multirow{3}{*}{1.6} & \multirow{3}{*}{0.5} \\
\hline Moderate & 14 & $18.6 \%$ & 5 & $10.4 \%$ & & \\
\hline Low & 16 & $21.4 \%$ & 11 & $22.9 \%$ & & \\
\hline
\end{tabular}

* Moderate and high level not present in depersonalization and accomplishment of burnout subscale respectively 
The Relationship between Burnout and Organizational Commitment among Nurses in hospital

Table (3) levels of staff nurses organizational commitment in emergency or intensive and general medical surgical units.

\begin{tabular}{|c|c|c|c|c|c|c|c|c|}
\hline \multirow{3}{*}{$\begin{array}{c}\text { Levels of Organizational } \\
\text { Commitment }\end{array}$} & \multicolumn{6}{|c|}{ Departments } & \multirow{3}{*}{ Chi- Square } & \multirow{3}{*}{ p-value } \\
\hline & \multicolumn{2}{|c|}{$\begin{array}{l}\begin{array}{r}\text { Emergency or intensive } \\
\text { care }\end{array} \\
(\mathrm{N}=75 \text { nurses })\end{array}$} & \multicolumn{2}{|c|}{$(\mathrm{N}=48 \text { nurses })^{\text {General }}$} & \multicolumn{2}{|c|}{ Total } & & \\
\hline & No & $\%$ & No & $\%$ & No & $\%$ & & \\
\hline High & 10 & 13.3 & 12 & 25.0 & 22 & 17.9 & \multirow{3}{*}{3.1} & \multirow{3}{*}{0.2} \\
\hline Moderate & 59 & 87.7 & 34 & 70.8 & 93 & 75.6 & & \\
\hline Low & $\bar{~} 6$ & 8.0 & 2 & 2.4 & 8 & 6.5 & & \\
\hline
\end{tabular}

Table (4) Correlation between level of organizational commitment and level of burnout component and years of experience of nurses.

\begin{tabular}{|c|c|c|c|c|}
\hline & \multicolumn{3}{|c|}{ Burnout components } & \multirow[b]{2}{*}{ Burnout } \\
\hline & Emotional Exhaustion & Depersonalization & Accomplishment & \\
\hline $\begin{array}{l}\text { Organizational Comn } \\
\mathrm{p}\end{array}$ & $\begin{array}{l}-0.36^{* *} \\
0.0001 \\
\end{array}$ & $\begin{array}{l}0.012 \\
0.890 \\
\end{array}$ & $\begin{array}{l}-0.42^{* *} \\
0.0002\end{array}$ & $\begin{array}{l}-0.333 \\
0.0001\end{array}$ \\
\hline $\begin{array}{l}\text { Years of experience } \\
\text { Correlation (r) } \\
\text { p- value }\end{array}$ & \multicolumn{3}{|c|}{ Organization commitment } & $\begin{array}{l}\text { Burnout } \\
\\
\\
-0.071 \\
0.440 \\
\end{array}$ \\
\hline
\end{tabular}

*significance $\mathrm{P}<0.05$

\section{Discussion}

Nursing profession is widely perceived as one of the most inherently stressful occupations, often characterized by high rates of staff turnover, absenteeism and burnout . ${ }^{(12)}$ Burnout is a psychological process of cognitive that occurs under conditions of severe stress and declares itself as an emotional exhaustion, depersonalization, and decreased motivation and performance improvements. Burnout disturbs the individual's balance first and then the organizational balance. The worst impact of burnout at the organizational level is destroying and diminishing organizational commitment among personnel and experts of the job. (Saini R et al 2011) $\left.{ }^{(18}\right)$,(Aghaei et al 2012) ${ }^{(11)}$, Shirazi et al 2010) ${ }^{(19)} \&$ Gemlike N et al 2010) ${ }^{(7)}$ So, the aim of the present study was to study the relationship between nurses burnout on organizational commitment among nurses in selected department at Tanta University Hospitals.

This study showed that two third of staff nurses $(66.6 \%)$ in general medical surgical units experienced high level of total burnout compared to $60 \%$ of staff nurses in emergency or intensive care units have the same level of total burnout Table (2) Vahey et al $(2004){ }^{(20)}$ nearly supported the present results and found that more than $40 \%$ of hospital staff nurses score in the high range for job-related burnout and more than 1 in 5 hospital staff nurses say they intend to leave their hospital jobs within 1 year. Olley, (2003) ${ }^{(21)}$ study indicated that nurses consistently reported higher scores on all measures of burnout compared to other health professionals . Furthermore, Browning et al (2007) ${ }^{(22)}$ adds that the prevalence of burnout among nurses who work in specialty areas such as oncology, mental health, emergency medicine and critical care are higher. On other hand, this finding is dissimilar to Abushaikha1(2009) ${ }^{(23)}$ who found that nurses reported moderate levels of burnout. Furthermore, the results of the present study are inline with (Fazelzadeh etal 2008) ${ }^{(3)}$ study who found that the total degree of reported burnout of study sample is thought to be moderate.

Burnout separated into three dimensions - emotional exhaustion, depersonalization and personal accomplishment (Peery, 2006) ${ }^{(24)}$ Results of this study showed that more than half of staff nurses in general medical surgical and emergency or intensive units experienced high level of emotional exhaustion. Perhaps nurses experience higher emotional exhaustion due to the amount of time they spend in direct patient care contact. Nurses, more than any other health care professional, spend more time in direct one-on-one contact with patients and their families and often dealing with emotional extremes within and between patient situations.

Additionally, due to longer and more frequent shifts, secondary to the current nursing shortage, nurses have less time for self-care and "down time" between working hours. This leads to physical, as well as emotional, exhaustion. Results of this study are supported by PEERY,2006) ${ }^{(24)}$ who found that study's sample exhibited greater degree of burnout in the dimension of emotional exhaustion than that of the normative national data for all helping professions. Further he found higher levels of emotional exhaustion in the nurses in the 
hospital-based units. The majority (61.62\%) of the nurses in this study sample was employed in a hospital and exhibited higher levels of emotional exhaustion than the normative data sample.

Results of this study showed that high percentage of staff nurses in general medical surgical departments experienced high level of emotional exhaustion higher than staff nurses in emergency or intensive care units $66.7 \%$ and $53.3 \%$ respectively) . These results may be attributed to increasing numbers of patients, and unfairness in working conditions, high patient acuity, lack of opportunities for professional development and feeling insufficiently trained for the job. In addition, to inadequate staffing levels, poor rostering, excessive workload, overcrowding, traumatic events, shift work, the frequency at which doctors rotate, inter-staff conflict, lack of teamwork and poor management skills( Vahey et al (2004) ${ }^{(20)}$.

Depersonalization tends to occur as a response to exhaustion. Nurses with depersonalization, attempt to distance themselves from they patients and their families by ignoring their unique qualities and avoiding engagement. individuals find the demands of their work more manageable when they consider the recipients of their care as impersonal objects. Unfortunately, prolonged depersonalization leads to indifference and cynical attitudes (Maslach et al., 2001) ${ }^{(25)}$.

Results of this study showed that all staff nurses in emergency or intensive care units experienced high level of depersonalization while $97.1 \%$ staff nurses in general medical surgical departments experienced the same level of depersonalization Table (2). These results supported by Al-Turki et al $(2010){ }^{(26)}$ who found that nurses exhibited high grade of depersonalization. This finding was congruent with Akroyd et al. (2000) ${ }^{(27)}$ who examined burnout in a group of radiation therapists and found they experienced higher levels of depersonalization. On the other hand, this finding is dissimilar to Delpas et al $(2011)^{(28)}$ who found that nurses had low level of depersonalization in his study.

Personal accomplishment is defined as "feelings of competence and successful achievement in one's work with people." (Peery,(2006) ${ }^{(24)}$ Results of this study showed that all staff nurses in general medical surgical departments experienced low level of accomplishment while $97.1 \%$ staff nurses in emergency or intensive care units experienced the same level of accomplishment this may due to increase stress and burnout due to excessive work load. Results of this study are supported by Abushaikha1 and. Hazboun (2009) ${ }^{(23)}$ who found that study samples experienced lower level of burnout in the dimension of personal accomplishment. On the other hand, this finding is dissimilar to Akroyd et al. $(2000){ }^{(27)}$ who examined burnout in a group of radiation therapists and found they experienced higher levels of personal accomplishment In a sample of radiographers, Akroyd et al. (2002) ${ }^{(29)}$ still found higher levels of personal accomplishment, but not as high as in the group of radiation therapists.

Results of this study showed that three fourth of staff nurses (75.6\%) have moderate level of total organizational commitment in emergency or intensive care units and general medical surgical departments this may be explained by the lack of other employment opportunities away from these hospitals that would attract nurses to go for better condition and higher salaries so they prefer staying in this hospital because it safe than other hospital or they prefer working in government hospital than other hospital . The Results of the study are consistent with Azeem( 2010) ${ }^{(30)}$ who found that the mean values of job satisfaction and organizational commitment are at moderate side. This finding is dissimilar to (Dorgham 2011) ${ }^{(31)}$ who found that studied subjects had low commitment to ward their hospital, also (Abood et al $(2011)^{(32)}$ who found that $77.3 \%$ of the nurses had high commitment.

Results of this study showed that there were no significant differences between staff nurses burnout in emergency or intensive care units and general medical surgical departments. the explanation of this result can be due to high level of burnout, bad work conditions, as work over load will decrease the motivation of staff to be committed. The Results of the study are consistent with (Shirazi etal 2011) ${ }^{(19)}$ who found that there was no significant difference in job burnout between the two groups. Also the results of this study showed that there were negative correlations between organizational commitment and emotional exhaustion $(r=-0.36)$. Also, there was statistical significant negative correlations between organizational commitment and accomplishment $(\mathrm{r}$ $=-0.42$ ). However, non-significant correlation was observed between organizational commitment and depersonalization The Results of the study are consistent with (Shirazi et al 2011) ${ }^{(19)}$ who found that one of the important findings in the literature of burnout was that organizational commitment is negatively related to job burnout as well as there is no significant relationship was observed between other organizational commitment components and job burnout .

In the present study there was negative correlation between burnout and years of experience. This may due to increase years of experience help nurse to recognize the natural of the work and environment. This consistent with Gemlike et al $(2010)^{(7)}$ high expectations in the early times of work are believed to cause organizational burnout. The people working for long periods in the same organizations may lose their self-trust, which subsequently bring the feeling to increase the continuance commitment level and stay in same organization to maintain the status quo. 


\section{Conclusion:}

It can be concluded that high percent of staff nurses in emergency or intensive care units and general medical surgical departments experienced high level of burnout and moderate level of organizational commitment. There were negative correlations between organizational commitment and Emotional Exhaustion and Accomplishment and total burnout. As well as there was negative correlation between burnout and years of experience. However, non-significant correlation was observed between organizational commitment and depersonalization.

\section{Recommendations:}

In the light of the findings, the following recommendations are suggested;

1-Work redesign plans as well as early assessment and intervention may be helpful in the reduction of job burnout in staff nurse working in hospitals

2-Stress management courses should be offered to all staff members with the goal to manage stress while it is in its early stages.

3-Regular communication skills workshop should be offered to all staff of the health care team.

4-It is also recommended that conflict management and assertiveness training should be attended by staff.

5-It is of utmost importance that reward systems are implemented in order to give recognition to staff members for the work they do.

6-Equal access for staff members to the attendance of in-service training, workshops and seminars should be implemented

7-Further research is needed in the area of burnout to understand the nurses understanding of burnout and investigate their needs to prevent burnout

\section{Acknowledgment}

The researchers gratefully acknowledge all nurses staff participated in this study in Tanta University Hospital

\section{References}

[1]. White, R A. Perceived Stressors, Coping Strategies, and Burnout Pertaining to Psychiatric Nurses Working on Locked Psychiatric Units. MASTER Thesis OF SCIENCE in Nursing, College of Health and Human Services, Eastern Michigan University, October 21, 2006;

[2]. Carolina DS. Correlates of job-related burnout in nurse managers working in hospitals. Doctor of Philosophy .Graduate Program in Nursing. New Jersey. 2010;

[3]. Fazelzadeh A., Mehdizadeh A. \& Sahraeeian A. Burnout in hospital nurses: a comparison of internal, surgery, psychiatry and burns wards. International Nursing Review ,2008;55, 62-67.

[4]. Hall E. Nurse Burnout in a high stress Health care Environment: prognosis better Than expected?2006; ${ }^{19)} 8$.

[5]. Aleandri A, Sansoni J, (2006), nurses and burnout : a survey in emergency department in the lazio Region. Prof Inferm. 59(3): 16570

[6]. Jennings B M.. Work Stress and Burnout Among Nurses: Role of the Work Environment and Working Conditions Agency for Healthcare Research and Quality, Chapter 26,2008.

[7]. Gemlike N, Sisman F A \& Sigri U. The relationship between burnout and organizational commitment among health sector staff in Turkey. Journal of Global Strategic Management | 08 | 2010, December

[8]. Malik M I, Zaheer , Khan M. A\& Ahmed M. Developing and Testing a Model of Burnout at Work and Turnover Intensions among Doctors in Pakistan. International Journal of Business and Management Vol. 5, No. 10; October 2010, 1833-8119 www.ccsenet.org/ijbm

[9]. Matin H Z, Kalali NS, Reza M \& khavan Anvari A. Do demographic variables moderate the relationship between job burnout and its consequences? Iranian Journal of Management Studies (IJMS) Vol.5, No.1, January 2012 PP: 47-62

[10]. SalahianA, Oreizi H R, Abedi M R \& SoltaniI. Burnout and relevant factors in organization . Interdisciplinary Journal of Contemporary Research in business VOL 3, NO 122012

[11]. Aghaei N, Moshiri K, and Shahrbanian S. Relationship between organizational justice and job burnout in employees of Sport and Youth Head Office of Tehran. Advances in Applied Science Research, 2012, 3 (4):2438-2445

[12]. Singh B, Gupta P.K\& Venugopal S . Organizational commitment: Revisited. Journal of the Indian Academy of Applied Psychology, January 2008, Vol. 34, No.1, 57-682008

[13]. Meyer, J.P., Allen, N.J. and Gellatly, I. 1990. Affective and continuance commitment to organization. Journal of Applied Psychology, 75(6):710-720.

[14]. El-Shaer AM. Staff nurses perception of job empowerment and organizational commitment at Mansoura University Hospital . Master Thesis, Cairo University, Faculty of nursing.2002:32,9-10appendex

[15]. Kalliny M., Ograk, H.U\& Saran, A Management styles and commitment: A Cross-Cultural Study. www.jgbm.org/page/1\%20\%20Kalliny.pdf

[16]. Meyer, J.P. and Allen, N.J. 1991. A three-component conceptualization of organization commitment. Human Resource Management Review, 1(1):61-89.

[17]. Abd Elghany F. (2003). burnout and coping strategies among nurses in speciality units. master thesis. Menofyia University

[18]. Saini R, Kaur S\&Das K Assessment of stress and burnout among intensive care nurses at a tertiary care hospital. Journal of Mental Health and Human Behaviour : 2011; 16(1)

[19]. ShiraziRR, BeikiY, Zamanian F\& Esapour K. Study of the relationship between organizational commitment and Job Burnout among Physical Education Teachers of Golestan Province, Iran. Australian Journal of Basic and Applied Sciences, 5(10): 13791384,2011 
[20]. Vahey D ., Aiken L H., Sloane D M., Clarke S P, and Vargas D. Nurse Burnout and patient satisfaction. medical care . Volume 42, Number 2 suppl, February 2004 .II-57. Copyright (C) 2004 by Lippincott Williams \& Wilkins

[21]. Olley, B.O. 2003. A comparative study of burnout syndrome among health professionals in a Nigerian teaching hospital. African Journal of Medicine \& Medical Science, 32(3):297- 302.

[22]. Browning. C., Thomas, S., Greenberg, M. \& Rolniak, S. 2007. Nursing specialty and burnout. Psychology Health Medicine, 12(2):148-154.

[23]. Abushaikha L\& Hazboun HS .Job satisfaction and burnout among Palestinian nurses. La Revue de Santé de la Méditerranée orientale, Vol. 15, $\mathrm{N}^{\circ} 1,2009$

[24]. Peery AI. Caring and burnout in registered nurses: What's THE Connection? Graduate school Of North Carolina State University Degree of Doctor of Education 2006:64-72

[25]. Maslach, C., Schaufeli, W. B. \& Leiter, M. P. (2001). Job burnout. Annual Review of Psychology (Annual 2001$)$, $397-419$.

[26]. Al-Turki, Rasha A. Al-Turki1, Hiba A. Al-Dardas1, Manal R. Al-Gazal1, Ghada H. Al-Maghrabi I, Nawal H. Al-EniziI, Basema A. Ghareeb1 Burnout syndrome among multinational nurses working in Saudi Arabia Annals of African Medicine Vol. 9, OctoberDecember, 2010:226-229

[27]. Akroyd, D. \& Adams, R. D. (2000). The cost of caring: A national study of burnout in radiation therapists. Radiation Therapist, 9 (2), 123-130

[28]. Delpas M, , Raeissi P, Begdeli F\& Shahabi M.The impact of job otation on nurses' burnout in Ayatollah Kashani Hospital,Tehran: A case study. Iran Occupational Health, Vol. 7, No. 4, Winter 2011:76-8

[29]. Akroyd, D., Caison, A. and Adams, R. (2002). Patterns of burnout among U.S. radiographers. Radiologic Technology, 73 (3), 215 223.

[30]. Azeem, SM. (2010). Job Satisfaction and organizational commitment among Employees in the Sultanate of Oman. Psychology,1,295-299.doi: 10.4236/psych.2010.14038.Published Online October 2010 .

[31]. Dorgham Sh R. Relationship between organization work climate \& staff nurses organizational commitment . Nature and Science 2012;10(5):80-91]. (ISSN: 1545-0740). http://www.sciencepub.net/nature. 